\title{
CEREBRAL MECHANISM OF SPEECH
}

\section{AND THOUGHT.}

BT

WILLIAM HENRY BROADBENT, M.D., F.R.C.P., PHYBICIAN TO, AND JOINT IBOTORER ON MRDICINE AT, BT. MARY's HOSPITAL, AND PHYBICLAN TO THE LONDON FEVER HOSPITAL.

Received Jannary 31st-Read February 13th, 1872.

Tre question of the association of loss of speech with lesion of a particular convolution in the left hemisphere of the brain has not been formally discussed by the Royal Medical and Chirurgical Society ; the close functional relation between the left third frontal gyrus and speech has, however, been implied in papers read before the Society. This relation has been the starting-point of the investigations and speculations contained in the present communication, and may in a certain sense be said to form the basis of the main conclusions here stated, though many are essentially independent of it. The objects of the communication are by means of the light thrown upon cerebral physiology by cases of loss or derangement of speech to construct a theory of the mechanism of speech and thought, and to connect this with the facts of cerebral structure so far as at present ascertained. If the nervous system is the instrument of 
language and of thought, then the objective aspect of the operations concerned in what are subjectively mental processes will be changes in cells and fibres, and we shall understand the physiology of intellectual operations only so far as we can represent them in terms of cells and fibres.

The following cases are first related partly as additional evidence of the association of a certain factor in the expression of thought by language, with the left third froistal gyrus, some of them as remarkable and interesting in themselves, and as affording a new insight into the mental processes of which language is a resultant.

CaSe 1. Right hemiplegia, with loss of speech and writing; hemiplegia fugitive; loss of speech permanent, except as to a few words mostly used emotionally; evidence of remarkable degree of intelligence and energy. Lesion in two parts of upper edge of fissure of Sylvius in left hemisphere; viz., posterior end of third frontal convolution and lowermargin of supramarginal lobule, the latter extending to the adjacent convolutions of the island of Reil; atrophy of tail of corpus striatum. -Mrs. W. B-, æt. about 70, was under my observation from time to time from July, 1868, till her death in August, 1871. The patient was a widow lady, and at the time of the seizure she was away from home for her health, and had just returned at 8 p.m. on July 26th, 1867, from a walk with a friend.

The attack was immediate and attended with complete loss of consciousness. She was placed on a sofa, where she was found next day still unconscious, having, however, about 4. a.m. manifested consciousness by pointing to her night dress and to the sofa as if to inquire how it was she was there. In the evening she recognised her relatives, and by her movements expressed great joy; later in the evening she made them understand, by pointing to her own pocket, and putting her hand into her sister-in-law's and taking out her purse, that she missed her purse and had no money. She was hemiplegic on the right side and quite speechless, trying to talk and angry that she was not understood. By the middle of the 
following week she was able to walk upstairs, and in another week to return home, a distance of 100 miles or more.

On her return she spent several months among her friends but she was very restless and dissatisfied. She had by this time quite recovered the use of her limbs and regained a few words. Her relatives treated her as if she were utterly incapable of looking after her own affairs, and especially of taking charge of her own money. This was a great grievance, and when her husband's relatives visited her she tried to make it known by showing her purse and repeating excitedly, "Oh, shameful! shameful!" She had an intense dislike to her attendant, and when she left the room would often point in the direction in which she had gone, shaking her head and exclaiming with great energy, "Oh! nasty! nasty!" following it up by a long story in which there was not a single word intelligible. At length she went to the neighbourhood in which her husband's relatives lived, a distance of sixty or eighty miles, without any house having been taken for her or any preparations made, and indeed without any warning.

A house was now taken and furnished for her, and she showed herself quite competent in making all arrangements about it, and when settled in it with a new housekeeper she seemed quite contented. Her principal topic of attempted conversation for several months was her niece and brother's bad behaviour to her. She laboured hard to make the friends among whom she now was understand her grievances. She would point out her relatives' names, or refer to their letters, or in some other way show to whom she referred, and then in great excitement would exclaim, " $\mathrm{Oh}$, Shameful! shameful !" then she would turn over letters and newspapers, and when she had tried in vain for hours to convey what she wished, she would shed tears, and say "Oh, pity, pity!" At length her banker's pass-book was obtained from her niece, and she scarcely knew how to express her joy. "I tried, and I tried," she said over and over again. But there was still something she wished to explain, and one day, while trying very hard as usual, she made the figures 40 quite distinctly, and it was understood at last that it was 
something about $£ 40$, but it was not till a friend came to see her, and this happened to be mentioned, that it was discovered she had put $£ 40$ into a bank before her attack, and believed her niece had the acknowledgment of it and some promissory notes with other papers. These she wished to be sent for, and eventually they were obtained. This was nearly a year after her removal, and all the time she had persevered in her attempts at an explanation. During the same time she had been making a new will, and week after week would have her sister-in-law to write out the different clauses. It often took a long time to do it to her satisfaction, but she never rested till every particular was exactly as she wished it; when the right guess was made she showed her satisfaction quite unmistakeably by her gestures, and by saying "Yes, yes, that's it."

These details are given because they convey an excellent idea of her mental power. Here it was clear that the patient formed a very definite mental picture of the words she wished to use as well as the meaning she wished to convey, and that she not only wished and willed vigorously, but propositionized very definitely. That she knew what word she wanted was shown by her resorting to letters, and sometimes to a dictionary; and in one of my visits, wishing to recommend a linseed-meal poultice, and failing to convey her meaning, she went for the housekeeping book, and found an old entry of linseed meal. She also pointed out to me newspaper paragraphs which interested her. She frequently read, but preferred being read to. Common expressions which she retained were "that's right," "pity, pity." When a nephew or niece called, would say "How d'ye do?" " that's right." How's your mother ?" repeating this question, or "How's your poor mother?" as an inquiry about the father, as she could not say this word. These phrases came out very rapidly and interjectionally. Sometimes under excitement she would acquire a new word, as once when several nieces sat down with her to tea, to her great delight, she exclaimed repeatedly "beautiful, beautiful." Inquiring about nieces she used the word " Anne." Wishing 
to name any place whatever, she generally said "Burling. ton," where she lived as a child.

She was quite unable to write, or even to sign her name. She once wrote down the figures 40 , as related, and sometimes wishing to divide money would make the proper number of marks to indicate the amount of a share.

At 8 a.m. on August 7th, 1871, she appeared as well as usual, and said she had had a good night. An hour later she was found to be paralysed on the left side, and absolutely speechless, and she so continued till her death on August 12th, quite sensible, and manifesting concern for her attendants, but refusing food. When fluids were put into the mouth, unless carried quite into the throat, they returned; probably her refusal of food was due to difficulty of swallowing.

I made the post-mortem examination fourteen hours after death, with the assistance of my friend Dr. T. Kilner Clarke, the head only being examined.

There was much fluid on the surface of the hemispheres, which were evidently shrunken from senile atrophy. There was a considerable amount of flùid also in the ventricles. The vessels were comparatively little diseased, presenting here and there hard opaque patches and dilatations, but mostly soft and of normal size and appearance.

In the right hemisphere no morbid condition was discovered to account for the final left hemiplegia.

In the left hemisphere the lower end of the first ascending parietal convolution (or ascending frontal gyrus of some authors), abutting on the fissure of Sylvius, and a very small part of the adjacent posterior end of the third or inferior frontal gyrus were gone, and in their place was a hollow space occupied by fibrous tissue. The cavity might hold a nut, and had obviously shrunken by the falling in of the parts forming its walls. Again, in the supra-marginal lohule over the posterior end of the fissure of Sylvius, was another hollow filled with connective tissue, and when the fissure itself was opened out it was found to contain, at this part, a superabundance of connective tissue, and the convolutions of the 
posterior end of the island of Reil were completely atrophied (they are here small and superficial). The gap in the lower end of the anterior parietal convolution corresponded with the posterior of the two lateral gyri of the insula.

In the ventricle the anterior end of the corpus striatum was plump and firm; but just where it begins to narrow and to overlap the thalamus, it suddenly became soft, and it might be said that from this point backwards the entire tail of the intra-ventricular corpus striatum was atrophied. (The part destroyed would correspond to the posterior of the two hæmorrhages in the wall of the Sylvian fissure.)

CASE 2.- Fracture of right petrous bone, Dec. 8th. Incipient paralysis of right face, Jan. 5th. Incipient loss of speech and writing, 8th. Complete loss of speech and writing, with slight paralysis of right limbs, 14th. Decided right hemiplegia, 16th. Death, March 18th. Abscess in substance of left frontal lobe; Surface of third frontal convolution, and convolutions of island of Reil not affected. White fibres cut across deeply.-William $\mathrm{D}$-, æt. 42 , carpenter, was admitted into St. Mary's Hospital, under the care of Mr. Lane, December 23rd, 1869.

On December 8th, fifteen days before admission, after having had "drink," fell down an area, was stunned, and remained unconscious for three quarters of an hour; bled freely from the nose and right ear. Subsequently a large quantity of clear fluid ("pints") flowed from the right ear. $\mathrm{Up}$ to the date of his admission he complained simply of headache, giddiness, and great weakness. On admission he was sensible, spoke well, had no paralysis, but was giddy; had pain in the right side of the head, and was quite deaf in the right ear. He lay in bed dozing, and paying no attention to what was going on, only complaining of headache when asked about it, presenting no other symptoms till January 5th, 1870, when slight paralysis of the right face was observed.

On January 8th, a month after the accident, the paralysis in the right side of the face was more marked, and some 
hesitation and difficulty in completing his sentences were noticed. He would give the first few words of his reply to a question, and then become confused and use wrong words. When something was given him to read the first word was correct, the rest of the sentence nonsense. He was surprised and amused at this, and also that he was unable to write his name when told to try.

At this time there was no paralysis of the right limbs, but the paralysis of the face was recognised as hemiplegic, i.e., as due to lesion in the left corpus striatum, and not to damage of the portio dura, the orbicularis oculi not being affected.

14th.-Paralysis of right face still more marked; slight hesitation observed in taking hold of any object with the right hand. Speech almost completely lost, unable to say anything but "Yes" and "No."

16th.-Right arm and leg almost completely paralysed as well as face. He lay on his back, the head and eyes turned to left, but readily carried to the right. When told to put out the tongue he opened his mouth at once, and the tongue moved to and fro, but was usually some little time before it protruded itself; then, however, it came out well, and with little deviation. Pupil of left eye larger than that of right, and sluggish ; urine and fæces passed in bed.

It could not be satisfactorily ascertained whether sensation was impaired or not; it was certainly not lost. No definite conclusion could be come to as to the sense of smell after repeated attempts to test it.

When asked questions requiring "Yes" or "No" for answer, replied by monosyllables, which could be distinguished as intended for "Yes" and "No" respectively. To questions requiring for answer a phrase, however simple, he could only reply by an inarticulate mutter, in which no words were distinguishable. He would smack his lips or tongue and try again, and eventually would smile at his failure. The more prolonged the examination the worse he became.

I concluded after careful examination that he not only 
understood what was said to him, and knew what meaning he wished to convey in reply, but that he knew what words he wished to say, though unable to utter them. This is, of course, simply an inference.

In the course of the case some new features presented themselves. On the 19th and 20th January he vomited his food. On the 20th a slight twitching of the muscles of the right side of the face was noticed. This became very marked, especially in his attempts to speak, the angle of the mouth being drawn rapidly and vigorously to the right every few seconds : this movement ceased during sleep. At times he called out loudly in the night, whether voluntarily or unconsciously could not be ascertained.

During the second week of February it was noticed that when asked a question he would apparently try to recollect what he wished to say; his face would assume the expression with which we are familiar when an effort is being made to recall something to memory, and he would sometimes put his hand to his head. This was not as he did at first, when he would reply promptly but inarticulately.

On February 19th, when I asked him his address, he repeated two or three times "My address," "My address," and finally, on failing to give it, said " $\mathrm{Oh}$, deary me."

On February 2lst there was a degree of improvement beyond anything previously seen. He answered, when asked how he was, "Quite well," "Quite well, thank you." Was unable to give his name or address, but repeated after me "Day," " William," " William Day," and after the last said "that's it," i.e. his name. Asked what he had had to breakfast, answered, after a time, "Can't tell." Tea? "Yes," repeated after me "tea," and then said "I had some pea." We had a similar conversation about bread and butter, but he could not repeat these words. On my asking him if he liked beer, and would wish to have some, he cried a little, and then said twice, "That's a thing I so like."

24th.-Answered "pretty well," when asked how he was, and gave several short answers correctly and distinctly. Could not give name and address; asked if he had forgotten 
them, said "Yes." Could not tell what he had had to breakfast. Could not name a pen, finger, or hat when the object was held before him ; to the hand, said " a plain hand."

He remained in much the same condition, completely paralysed as to the right limbs, eating and drinking well, but passing his urine and fæces in bed, till about the end of February, when he began to vomit his food and grow weaker. He answered questions less readily ; would reply "very bad" when asked as to his condition. He gradually sank, and died March 18th.

Post-mortem examination fourteen hours after death.When arch of cranium removed, outer surface of dura mater seen to be red, injected, and granular; inner surface of bone red and rough over greater part of vault. Fracture through right petrous bone.

Pia mater and arachnoid pale and anæmic; dura mater adherent to other membranes over posterior end of second left frontal convolution. Left frontal lobe seen to bulge outwards, and second frontal gyrus flattened and expanded from within. First and third frontal convolutions not altered on surface; apparently normal. Fissure of Sylvius slightly glued up, but convolutions of island of Reil and all the parts within the fissure presented normal appearance. No great amount of fluid in the ventricles; when the frontal ends of the two hemispheres were drawn apart, strong adhesions were found to exist between them where they come into contact below the narrow end of the falx major, and the left bulged considerably, encroaching on the right.

Fluctuation evident in left frontal lobe, and an incision along the second frontal gyrus, where the wall of the cavity was thinnest, penetrated an abscess of considerable size, the parietes of which were tough and dense, the contents "laudable" pus, with broken-down cerebral matter. The abscess extended deeply into the axis of this end of the hemisphere, and invaded the white substance of the third frontal convolution along its entire length.

This is one of the cases which have sometimes been considered exceptional. It is interesting on this ground, and 
also on account of the partial return of speech, which, taken in connection with the healthy state of the cortical substance while the white fibres were cut across, suggests the speculation that some other way round was being opened.

CASE 3. Right hemiplegia; absolute loss of speech and of voice; embolism of right carotid and of left middle cerebral; softening of outer part of left corpus striatum, and of adjacent white substance of hemisphere.-Mary S-, æt. 27, a lady's maid, was admitted into St. Mary's Hospital June 7th, 1870. She had had an attack of acute rheumatism seven years before and had never been well since; was known to suffer from heart disease. Her recent history was imperfectly obtained, but it was ascertained that she had been suffering from pains in the joints, and especially in the feet; her breath was short, and she sighed frequently; she had a short time before the attack spit up some blood. She gave up her situation and came to London in April ; had since then been able to crawl about, but not to leave the house.

On May 29th she lost her speech for a few minutes.

On May 30th lost the use of the right side, and speech suddenly without convulsion or loss of consciousness.

There was no important variation in her condition from the time of her admission to her death on June 22nd. The motor paralysis of the right limbs was complete, and was attended with slight rigidity, which seemed to increase. Straightening the flexed fingers and movement of the leg gave pain ; there was a little movement when the sole of the foot was tickled. The paralysis of the face was very evident, and had the usual characteristics of facial hemiplegia. The tongue was protruded very slowly, and not far enough to exhibit much deviation. A pinch on any part of the affected side was felt.

The right forehead was at times observed to be moist when the left was dry; the right cheek was the more flushed; there were larger sudamina on the right than on the left abdomen. Urine and fæces passed in bed. Systolic murmur heard over apex of heart, and from this to lower sternum. 
Her expression was placid, a little wistful when she was questioned, but never anxious or suffering. She followed one about with her eyes equally well in all directions, and not unfrequently smiled. She did not speak a single word or utter a sound, though at times she tried, and her lips moved. She nodded for affirmation, and shook her head for no. Seemed to understand all that was said, and to be puzzled how to reply. Asked if she could read or write before her illness ; signified " no" with a smile. Asked if father and mother alive. Tried to say something, but in vain. At times I had doubts whether she quite understood my questions.

Temperature $99^{\circ}$ on June 7 th, $104^{\circ}$ on 17 th, $107 \cdot 8^{\circ}$ on 22nd, day of death.

Post-mortem appearances. - Extensive deposit on mitral valves. Surface of cerebral hemispheres much injected, especially the left, on which there were apparently minute extravasations. No superficial softening. A plug in right carotid, just as it emerged from the cavernous sinus, obliterating the vessel for a short distance, firm, yellow, and apparently of old date. The canal of the vessel beyond it was open and in communication with the posterior communicating artery, which was enlarged. There was a plug also in the left middle cerebral artery just within the fissure of Sylvius, completely blocking up the vessel.

On examining the corpus striatum of this left side in the ventricle a well-defined yellow patch with a sinuous boundary was seen along the outer side for about one half or two thirds of its length, but not extending round the anterior end, and involving about one third of the breadth. Continuous with this was a softened portion of the white substance of the hemisphere lying above and to the outer side of the corpus striatum, and about the size of a cob-nut.

CASE 4. Congenital aphasia.-William T-, æt. 11, was brought to St. Mary's Hospital for alopecia areata, February 17th, 1870. He was a bright, intelligent-looking boy, but had never talked. I kept him under observation for more 
than twelve months, and condense and arrange the following information from my notes made at different times :

$\mathrm{He}$ is the fifth of nine children, five of whom are now alive and well; two, the eighth and ninth, were born dead, one died of convulsions, another of scarlatina. The father died of phthisis; mother living, and well. He was delicate as a child, but never had convulsions or any serious illness ; was run over at the age of six years and hurt on the left side of the head and "in left leg; he had not talked before the accident.

Face intelligent, eyes bright, and remind one of an intelligent dog from the keen way in which he watches one's face and movements. Nose broad and rather misshapen; central incisors well formed and not notched, lateral rather pegged. Head of good size and shape, but when looked at from above, left frontal region seems to be smaller than right.

Facts as to general intelligence.-He plays with other children; is irritable and passionate with younger children, trembles when excited, but is obedient and manageable. He can find his way about the streets, even to places he does not know, if the name is written for him. Can be sent errands with a note, will know what he is sent for, and refuse anything else; will see that he has the proper change if told beforehand how much it should be.

Facts as to speech and writing.-He clearly understands everything that is said to him, but cannot utter a single connected sentence, and has never talked. To most questions he answers by a sound which may be represented by "keegurkruger," whether the required answer be long or short. $\mathrm{He}$ says " no" distinctly, "yes" indistinctly, that is, without the y or s; helping out the meaning by an affirmative nod. He always gave these replies appropriately. Says "father" and " mother," substituting $\nabla$ for th, and dropping the final $r$. These, with "dunno" for don't know, were all the words which could be got from him at his first visit. Asked name, address, how long the state of the head had existed, \&c. \&c. he answered "keeger-kruger." 
He wrote his name pretty well, and copied several words from a printed card in written characters, but could not write yes or no when told to do so ; could not write the name of the street in which he lived. Did not understand on this or any occasion the simplest written request, such as "Pick up the pen," "Put out your tongue." When word "pen" was written, and he asked what it meant, he named the letters, but had no idea what was signified.

His mother took great pains to teach him to speak. At one time he could, when asked his name and address, utter sounds evidently intended and capable of being identified as William T-, Circus Street; at subsequent visits he gave only "keegur-kruger." Another time, after having been frequently and urgently asked father and mother's name during one visit, at the next, when asked, said, "Faver dead -I got no faver." On this occasion also asked how he was, replied pretty distinctly, "All right, thank you." These phrases were subsequently entirely lost.

At different times he wrote for the word "no" "baleve" and "acbe ;" for it, " is ;" for card, "ke ;" for "I am well," "waern ;" for "I am better," began to copy the date 24th November which caught his eye.

A curious inconsistency was shown with regard to numbers. When asked his age he would write in large 12 on the palm of one hand with the finger of the other, and he wrote it correctly with the pen. When his mother removed from 25 to 41 he showed the new number by making a large 4 and 1 with his finger on the table. I wrote 41, and he said "yes." A subsequent change to No. 10 he indicated in the same way. Asked one day what time he left home, said "one o'clock" pretty distinctly. Another day asked the time by my watch at $2^{\circ} 45^{\prime}$ ', said "free o'clock ;" afterwards, when told he was not quite right, "About half past two ;" the words indistinct, but the intended meaning clear.

He could protrude the tongue and move it freely in all directions. He could produce after me all the vowel sounds, and with a little trouble, could say ba, be, bi, \&c., through the alphabet. 
The case may, I think, be fairly called one of aphasia. The difficulty was obviously not articulatory merely; on the other hand, the boy was not an idiot in any sense, and was not speechless through a general deficiency of intelligence; he understood what was said to him, and copied printed words in written characters, but had not apparently associated the written sign with the verbal sound so as to understand written or printed words, though, curiously enough, he did this in the case of numerals. The failure seemed to me to consist in an absence of the faculty of mental rehearsal of phrases; he could not formulate volitions in words, or as Dr. Hughlings Jackson has put it, he could not propositionize.

CASE 5. Partial right hemiplegia with loss of speech, apparently from embolism. - Sarah Ann C-, æt. 22, married, was admitted into St. Mary's Hospital May 5th, 1866. She had been confined of her first child two months before, losing much blood afterwards, and she had since had neither spirits nor strength, and had been unable to suckle her child. At about midnight on Friday May 4th, she leaped out of bed and fell down, the fæces and urine escaping involuntarily. It could not be ascertained whether there had been any convulsions, but she was lifted into bed in an unconscious state, and was so found by her mother, my informant, in the morning. She neither spoke nor moved, and her head and hands when raised dropped as if dead. On arriving at the Hospital, however, she was tossing her arms about, and muttering "No" to all questions. She was considered by the house-surgeon to be hysterical and treated accordingly; but in the ward it was noticed that she did not move the right arm so freely as the left, and that her face was drawn to the left when she smiled. In the evening she got out of bed and walked to the door of the ward, was caught by the nurse, treated with cold water, after which she became quiet and passed a good night.

There was evidence of paralysis in the right face; the patient could move the right arm freely, but had only a very feeble grasp. She could walk, but dragged the leg; the 
evidence as to sensation was uncertain. The only word she could utter was "No," but she signified yes and no by signs. she did not seem to understand fully all the questions put to her; was very emotional but struggled against the tendency and controlled herself well. She could write her name, but nothing else.

In a week, i.e. May 11th, she had gained power in the paralysed limbs and acquired a few new words, "Yes,". "Nurse," "Nicely."

May 17th.-Has regained more words, but as she acquires some loses others, Repeats perpetually and often quite mal à propos "just like that ;" repeats long phrases after a particular fellow patient, not after any one else. Mental condition peculiar and difficult to characterise. She understood what was said to her, did not seem to notice what was said about her ; very emotional, exhibiting her feelings by exaggerated facial expression and by gestures, but did not give way to them; sobbed sometimes when told she might recover, or when her child was spoken of, but did not cry. Her mother coming in showed her the child's petticoat; she started, pushed it away with an expression of aversion, exclaiming "No," and turned away, taking no further notice of her mother, though I was talking with her for some time. Afterwards, when asked if she would like to see the child, seemed affected and indicated a wish to do so.

She improved in speaking, and by May 25th was able to carry on a conversation, though occasionally at a loss for a word. She had always looked ill and now became rapidly worse; the urine was highly albuminous, œdema of the lungs and general dropsy came on, and she died early in July. Unfortunately no post-mortem examination was permitted.

CaSE 6. Right hemiplegia with loss of speech and writing apparently from embolism.-George $\mathrm{L}$-, æt. 29, single, a coachman, was admitted under the care of Dr. Sieveking, April 3rd, 1870. Had fits when a child, last at the age of seven; rheumatic fever twelve months ago, after which he was quite well for six months, but for the last six months he had com- 
plained of numbness and coldness in the right leg, had constantly sought the fire, and had fallen off in his appetite.

He was at work up to two days before the attack, but lately looked bewildered. During the two days he had not been able to work, he talked incessantly all sorts of nonsense ; said the room and various objects were larger than natural. "Oh my, how big the table is, and the chairs," then laughed ; told ridiculous stories.

The attack came on in the night, his brother awoke and found him in violent convulsions, mostly of legs, not more one side than other ; face drawn, eyes wild, stertor, frothing at mouth, no cry. The attack lasted two hours; when it was over right hemiplegia with loss of speech established. On admission the paralysis was complete, the loss of speech absolute; and he could not protrude the tongue. He gradually gained some power in the leg so as to be able to walk about, but the arm remained motionless and flaccid. He could now also say yes and no, but was not always right in his use of these words. On one occasion he twice said "Here," to his sister when impatient that she had not complied with his wish for her to come to him. Could write his name but nothing else, and wrote it when asked to write an answer to a simple question. The case presented no peculiar features, and is here recorded partly as an example of a rather unusual type of attack in embolism, partly for the purpose of noting that the patient while in the condition described read the newspapers much with apparent interest, and at my request he pointed out a Crystal Palace advertisement of fireworks, and an account of pigeon shooting at Hurlingham, the latter very promptly and with a pleased expression, as if he had already read and enjoyed it.

CASE 7. Right hemiplegia with loss of speech and writing, presenting some peculiarities.-Herman $\mathrm{R}$-, æt. 34, a German, goldsmith, said to be very clever at his work and intelligent, was admitted into St. Mary's Hospital under the care of Dr. Sieveking, February, 1870.

He had given way to alcoholic and venereal excesses. Had 
acute rheumatism in 1865 , and had since suffered much from pain in the limbs, especially within the last month. He had had much headache also, and a fortnight previous to the attack had fallen down in the Park.

On Friday, February 6th, he fell off his stool while at work, was unconscious for about five minutes, then came to himself, but seemed powerless and answered questions reluctantly and indistinctly; he groaned much; no convulsion. A friend (German) who saw him next day had some difficulty in understanding what he said, and thought he mixed up English and German without knowing it. His landlady who attended on him did not notice this. On Sunday evening, February 6th, he was found to have lost the use of the right hand and arm and to be unable to speak at all. Notwithstanding this on Tuesday morning (the 8th) he got out of bed, dressed, except coat, shoes, and socks, went down seventy-two steps to the kitchen, where he sat down, and then, on being remonstrated with by his alarmed landlady, walked back, undressed and got into bed; all this without resistance and without saying a word. On the evening of this day he was brought to the hospital and was found to be incompletely hemiplegic on the right side and unable to answer questions so as to be understood. He soon began to improve and my notes on the 14th are as follows:-All his answers in a low smooth tone, without modulation of voice, he could not be induced to utter loudly even a word he could say. Answered "Yes" and "No;" told me his age correctly and his name, but indistinctly. Asked how he is, replies " better" or "quite well" rather indistinctly. "If he had pain in the head since the attack?" "No." Before, "Yes, wonderful." If he slept well, " Nicht" - . something or other which could not be made out. If appetite good, "No." What he liked best, a gesture expression of disgust, with words which could not be identified. It was impossible to understand him when he attempted a phrase, or when he tried to say anything to which I had no clue. He laboured through the title-page of a book given him to read, but, without looking at the book, only one or two words would have been recognised. A peculiarity of his

vol. $\mathbf{L V}$. 
attempts to read or speak was his persevering effort to master a word, syllable by syllable, by trying on and on again. For example, when asked to read the words diet-card his attempt was something like this, diget, dicht, dite, dite, dite car. The next moment he pointed to his name, saying, without hesitation though not very distinctly, "dat my name." A strong German accent was distinguishable in all he said, whereas before the attack he spoke English particularly well. Up to this time and a week later, February 21st, he could not sign his name, or write the simplest word such as yes or no when asked to do so, or copy a word pointed out to him. He remained in the hospital some weeks longer, recovering very fair power in the limbs, speaking better but very unequally at different times, frequently, however, energetically and with gesticulation. Within the last fẹw days of his stay he replied "garz wohl" for very well, and told me a long story in German, as I suppose, but in English as he insisted, of which I did not understand a word. He could now with great effort write his name.

The following case is a remarkable one.

CASE 8.-After an acute cerebral attack absolute inability to read printed or written words (except own name), while the patient wrote correctly from dictation and composed and wrote letters with a little prompting. Inability to recall the name of the most familiar object presented to his sight, while he conversed intelligently, employing an extensive and varied vocabulary, making few mistakes, but occasionally forgetting names of streets, persons, and objects. Death from apoplexy; extensive atheroma of cerebral vessels; old clots in substance of left hemisphere, with softening of adjacent substance to outer side of lateral ventricle at junction of descending cornu. Recent hamorrhage in same situation.-Charles D-, æt. 59, a gas collector, and member of the Paddington Vestry, came under my observation at St. Mary's Hospital on May 8th, 1871, under the following circumstances:-He had seen an accident in the street, and came to the hospital for the purpose of giving information, the case baving been 
admitted. His embarrassment of speech was noticed by the out-patient porter, who recommended him to see me next day. His first complaint was that he was unable to read; "I can see them," pointing to words, "but cannot understand." In reply to my questions he informed me that he had been a gas inspector, had " always been hearty till overworked;" had been ailing eighteen months or more, and at one time very dangerously ill. I found he could not remember names, and $I$ put down in my notes that he sometimes answered questions quite irrelevantly, e.g., asked if illness came on suddenly, began to speak of " right hand of grove," and was evidently trying to recollect the name of some street or of medical man. Later I discovered that "right hand of grove" referred to the residence of Dr. Algernon Norton, who had attended him in the attack he was trying to tell me of, and that the irrelevancy was only apparent. He tried to give me an account of the accident respecting which he had come to the hospital, but I was unable to make out what it was, partly at least, because he wished to include in it the name of the street in which it occurred and could not recollect it. On the other hand, he gave me a lucid description of an accident which had occurred to him as captain of a volunteer fire brigade, in which he, his son, and some of his men, had been caught beneath falling timbers, two men being killed and himself nearly bưrnt to death.

He was a fine well-built man, with dark curly hair and a good colour. He had a very intelligent face, and had evidently been possessed of great energy and force of character, taking a very active part in all public affairs, and much respected by all classes. He had been captain of a volunteer fire brigade, was an efficient volunteer when taken ill, and had for many years been elected to the Paddington Vestry where he was prominent and influential. He took a good deal of alcohol but did not get drunk.

He had never been quite the same man since the accident at the fire seven or eight years before, but had been in good health, except that for years he had been subject to head- 
aches, especially after worry, till January, 1870, when he had stoppage of the bowels from hernia. He recovered and resumed work, but " a fortnight before the Easter Volunteer Review," he was seized with sickness, vomiting, and pain in the head. The pain in the head was very severe, at one time in the temple, at another in the occipital region. He was delirious and restless, and did not know his wife for a fortnight. He gradually recovered, but after this attack was unable to read either print or writing, but could write quite well. He went on a visit to Chatham for change of air, and wrote good letters to his wife, my informant on the points now related. He told me later, however, that his sister used to assist him by hints. At Easter, 1871, he had pain in the abdomen, and after that time had not been able to write a letter, though he wrote correctly from dictation. He cannot bear a noise of any kind; no fits.

When tested as to his power of reading by means of the hospital out-patient card he was quite unable to make out St. Mary's Hospital printed in large type. He pointed to the letters one after another, and seemed to be making great and almost painful efforts to name them, but in vain. He said he could see them well enough but could " not understand them," could " not recollect them," could " not get them into his mind-box," employing these various phrases. At the same time he signed his name promptly, wrote "I can not do read ;" when asked to say in writing that he could not read (the "do" I think is accounted for by a change in expression suggested to him). He wrote from my dictation out of a vestry circular he produced, "The clerk to read letters and other communications," and on another occasion "This is to certify." He also took notes of my instructions, and of the day and hour of subsequent visits, which I saw were correct, telling me that he was very forgetful and might make mistakes. He would be utterly unable an hour later to read his own writing, but he relied on his wife making out the notes he took.

He recognised his own name, whether printed or written, but could not be sure whether the initials or full Christian 
names were given. He produced a printed list of the vestrymen and pointed out his name in it; recognised it again at once, written on the hospital card. When asked what the other writing on the card was, he inferred that it was the date (May 8th) ; counted on his fingers January, February, March, April, May, then stopped and said, "It must be the 9th."

He told me he forgot the names of places and persons, "the names of these," pointing to his legs and arms, and when asked he was unable to name his limbs. While he was trying to do this in an early part of his first visit, he said he came to know my name from that of Mr. Broadbridge of the vestry, adding, "Is that your name, sir?" On another occasion, said he could not recollect the name of these articles, taking hold of his coat. When I touched his coat and said, "Why, these are your trousers," he said at first "Yes," but then corrected himself, and said "Coat." On asking him just afterwards to name his finger, he muttered "Coat-hat-boot," then remained silent, trying to recall the name. I said, "It isn't your thumb, is it ?" He said, "Yes, thumb," but saw his error, and went on trying other words, and at length found " Finger."

Tested with various colours, he could not bring the name of the colour to mind, but when it was mentioned, he pounced upon it at once. Asked if an orange-coloured card was blue, green, \&c., said "No." Red, "Well, it is more red than anything else." Orange, "Yes," promptly, "Orange."

Tested by a circle and square, could not name either. When asked if the square was a circle, he said, "No, but that is," pointing to the proper figure.

On being asked how he spent his day, he replied, "Miserably ;" explaining that he was formerly very active, and now had nothing to do ; but he employed himself in anything he could find, "cleaning boots," \&c. \&c. He always attended the meetings of the vestry; he did not feel competent to take part in the discussions as he used to do, but it amused him, and he added, "but I daresay I am as useful as a good many of them still."

He went out a good deal and found his way about the 
streets, taking care not to be out at night. At a railway station could not remember where he wanted his ticket for, except sometimes when going to Chatham.

Formerly he liked to have the newspaper or a book read to him. Cannot bear it now ; "cannot understand properly ;" "cannot calculate what is said ;" cannot follow the sermon at church, asks his wife to cut the prayers short.

- The case may appear rather prolix, but I think it important to omit nothing which may throw light on the mental condition of the patient. He was under.observation till June 1st, and my notes of various interviews are condensed and arranged. He was a remarkably intelligent man, cheerful and energetic, even under his affliction; he employed in conversation a very extensive vocabulary, usually speaking fluently; sometimes stopped for want of a word, usually a name, rarely using wrong words, for which $I$ was on the look-out, the only ones I have notes of being "soup" for " supper," " nephew " for " grandson."

He ate, drank, and slept well; ha,d no pain, complained only of feeling weak. He was said to be thinner than he had been. There was no cardiac murmur; no sugar and no albumen in the urine, the sp. gr. of which was 1010 .

He took Hyd. Bichlorid., gr. $\frac{1}{10}$, with bark, three times a day, and was thought by himself and by his wife and sons to be improving in his recollection of names, \&c.

On the evening of June 21 st he went to a vestry meeting and returned in unusually good spirits. He had up to that time been much the same, and in the morning had counted accurately $£ 47$ in silver. At 10.30 p.m., just after his return from the vestry, he was left alone in a room for a short time, when groaning was heard, and he was found on the floor. He was not absolutely unconscious; when seen soon afterwards by Dr. Dale the pupils were remarkably contracted. On being raised into the sitting posture he vomited. A little later he was found by Mr. Herbert Norton and Dr. A. Norton to be quite insensible, and he died at 12.15 on June 23rd.

Post-mortem examination of head only permitted. Omitting unimportant particulars, the veins of the hemispheres 
were full. All the arteries, especially the basilar, most extensively diseased. Opacities everywhere; coats rigid; no obstruction. Pia mater thickened and opaque, especially over the upper part of the hemisphere posteriorly to the sulcus of Rolando on both sides. Membrane over fissure of Sylvius thick and tough on both sides, and over calcarine and internal parietal fissures on left side.

A red patch, caused by a thin layer of recently extravasated blood, was seen round the anterior end of the fissure of Sylvius on the right side, extending over part of 3rd frontal, anterior parietal, and infra-marginal convolutions, but not penetrating into the sulci or fissure.

Portions of convolutions cut out from the left hemisphere at the margin of the great longitudinal fissure just behind the sulcus of Rolando, showed the gray matter thin, pale, and shading off into the white substance. Elsewhere the gray substance was well characterised.

The left hemisphcre was soft and boggy to the feel, and the convolutions flattened. Blood was seen to have issued from the fourth ventricle between the medulla and cerebellum, and to have spread over the posterior part of the cerebellum, which on further examination proved to form part of an enormous extravasation, filling all the ventricles, but especially the left lateral ventricle, in the wall of which was the aperture by which it had entered the central cavities. In this ventricle was a clot of the size of a child's fist; the thalamus and corpus striatum were completely broken up; the blood had, in addition to this, penetrated into a large cavity in the temporo-sphenoidal lobe, which had apparently been partly formed by softening, but extended by the hæmorrhage, its anterior part being smooth, its posterior part ragged. It was on the outer side of the descending cornu, reached to within three quarters of an inch of the apex of the lobe anteriorly, posteriorly to about the junction of this lobe with the occipital, and its walls exhibited an interesting natural dissection of the fibræ proprix of the convolutions on the under surface of this part of the hemisphere. In the outer wall of this cavity were found two old clots; one about 
the size and shape of an almond was loosely embedded in the infra-marginal gyrus between the deep parallel sulcus on one side and the secondary small gyri on the lower wall of the fissure of Sylvius on the other, about opposite the junction of the upper third with the lower two thirds of the descending cornu. The other was farther back and on a higher level, almost exactly corresponding in situation with the posterior end of the fissure of Sylvius externally, and with the junction of the descending cornu with the body of the ventricle internally; in fact, it occupied the thickness of brain substance separating the extremity of the fissure from the ventricle. It was about the size of a bean, yellow, very tough, fixed by puckered pia mater and by vessels entering the brain substance at this point, and it formed part of the wall of the great cavity in the temporo-sphenoidal lobe, the brain substance around it being softened. No abnormal appearances in any other part of the encephalon.

It is to the clot last described that I wish to call particular attention. From its relation to vessels entering the substance of the hemisphere, and from its position with respect to the cavity in the temporo-sphenoidal lobe, I consider it to have been the cause of the softening of which there was here evidence. Unfortunately the extent of the softening could not be ascertained in consequence of the recent hæmorrhage which had ploughed up the lobe. The blood recently effused must either have come from the wall of this softened portion, and thence burst into the ventricle, or have penetrated it early, since it had been entirely excluded from the adjacent descending cornu by pressure from the cavity, which lay along its outer side, while all the other cornua on both sides were greatly distended by it. But the clot, moreover, occupied a very important situation in the hemisphere, and would involve important sets of fibres, viz. the fibres from the thalamus, crus, and corpus striatum (named in the order of their abundance), which curve round the upper end of the descending cornu to the occipital lobe, and also the fibres which, converging towards this point from the infra-marginal and parallel gyri of the temporo-sphenoidal lobe, here curve 
upwards and turn forwards deeply in the parietal lobe to be distributed to the parietal and frontal convolutions. It would involve also fibres of the corpus collosum, both from the body of this commissure and from the reflection which I have called the commissure of the hippocampi, passing mainly to the temporo-sphenoidal lobe.

I do not, of course, conclude that the peculiar affection of the mental faculties exhibited by this patient were due to this hæmorrhage and the adjacent softening, but $I$ point out the coincidence of a peculiar and important loss of function with lesion in an important knot of cerebral fibres, in the hope that attention will be drawn to the point and further evidence obtained.

CASE 9. Temporary loss of comprehension of spoken words after apoplectiform seizures.-Miss $\mathrm{O}-$, a maiden lady, æt. 58, was seen by me in consultation with Mr. Wall, October 29th, 1870. She had fallen down unconscious about ten months previously, recovering herself immediately. On September 12th she was found lying on the floor insensible and breathing stertorously, bleeding also from the nose. On regaining consciousness her naturally cheerful expression was exchanged for a dull stolid look; she took no notice of anything; did not seem to understand what was said, e.g., when told to put out tongue, said: "Yes," and "I think so," but did not obey. Her entire speech consisted of a few short habitual expressions, such as "Yes, indeed," which she used without the least reference to what was asked. No paralysis; no cardiac murmur; no albumen in urine. She recovered her speech and intelligence and natural expression gradually in a few days to a very considerable degree, but was sometimes at a loss for words, had forgotten many names, and complained of deficiency in her memory generally.

On September 28th she had another similar, but less severe, attack, from which she recovered up to the same point; but on the 29th she was seized with pneumonia, which ran its course in about three weeks. She had lost her usual cheerfulness and sometimes cried, often missed out 
words in speaking, and was annoyed at it, and constantly made remarks without any obvious meaning.

On October 28th was seized with sickness early in the morning; fell into a state of semi-coma; did not recognise any one; could not be made to speak. When I saw her next day with Mr. Wall she sat up in bed, knew her friends, took notice of all that passed, but did not seem to understand what was said. She gave brief replies, always utterly inappropriate, using few words, but pronouncing them distinctly. On the other hand, she seemed to comprehend signs perfectly; put out her tongue promptly when her chin was touched, after having been repeatedly asked to do so in vain; held out her hand when I approached mine to feel the pulse, \&c.

She again recovered up to a certain point, but on November 3rd was attacked with bronchitis, from which she died on the 5th. No post-mortem examination was permitted.

CASE 10. Lead-poisoning; gout; epilepsy; right hemiplegia with loss of speech and of comprehension of language. Hemiplegia transient; loss of speech permanent; death from albuminuria and gangrene of left foot.-W-, a painter æt. 42, was seen by me with Dr. Felce, December 14th, 1871. He had had lead colic twenty years before; had been subject to gout for ten years, relieved from time to time by a specific tincture, but causing chalk stones in his knuckles and in the end of the thumb he used for graining. Three years before, in bed three months from rheumatism, so called, and unable to work for six months. Since then one week at work, another laid up by gout or rheumatism. For four or five years subject to epileptiform attacks at intervals of two to six months, always coming on at night. General bilateral convulsions with tongue-biting, followed by stupor.

During the night of October 14-15th, while lying on the right side, suddenly put out the left arm and began to jabber; then took hold of his right arm, which was quite useless. No convulsions ; no loss of consciousness. He was found by Dr. Felce, who was called to him, completely hemiplegic, with 
greatly impaired sensibility, keeping up a meaningless gabble, in which $\mathrm{m}$-sounds were predominant, and showing the paralysed arm. The attack was followed by much cerebral excitement shouting, violence, \&c. He soon regained power in the right limbs, but the speech was as imperfect as ever, and he was unable to write or to copy. Ulcerations were produced by very slight pressure about the right ankle and foot, and he suffered successively from severe jaundice, two or three attacks of gout, which were speedily relieved by iodide of potassium, spots of purpura over the entire surface, great œdema of the leg and scrotum, and finally gangrene of the left foot came on, preceded by intense pain in the whole limb. The urine was albuminous.

When seen by me with Dr. Felce on December 14th, he had for two or three days been very violent at times; had got out of bed repeatedly, notwithstanding the gangrenous state of the foot, had thrown a chamber utensil at his wife, and had sometimes shouted till completely exhausted. He received us with a profusion of bows and smiles, with gestures expressive of welcome. He looked much older than his years; was thin, and his eyes were yellow, but not his skin. He was apparently very cheerful, smiling, mumbling, gesticulating, winking with first one eye and then the other, and often showing the sclerotic above the cornea, all these being old tricks. His wife said he was more like a foreigner than an Englishman in these respects. His speech was a mere jabber, in which "Ma" and "Mum" were prominent, and was accompanied with an excess of gesticulation, smiles, and facial expression. The gestures were very striking and apparently appropriate when we had a key to their meaning, as, for example, when he wished his wife and sister to leave the room while he showed the state of his scrotum. It was stated that he said "Yes" or "No," and "Oh, my" at times; but he did not use even these simple words before us. He was unable to write his own name when his signature was before him. When urged to do so scribbled off rapidly something in which letters of some sort were distinguishable at first, but then tailing off into a scrawl. 
He obviously did not understand anything that was said to him, did not squeeze my hand on repeated requests, but went on shaking it and smiling; put out his tongue repeatedly when told to close the eyes, but instantly imitated the act after Dr. Felce, \&c. It was doubtful how far he recognised the state of his speech; he went on chattering as if he thought he was understood, but he also made signs. He howled loudly and long, and looked very fierce when the foot was uncovered for inspection.

There was very slight evidence of right hemiplegia in the face and arm. Pulse frequent and weak. Heart's action disproportionately powerful. No murmur, but first sound prolonged, and heart enlarged. Urine albuminous. Sp. gr. 1015. He remained in much the same state till his death, about Christmas, once startling some friends in conversation at his bedside by exclaiming " Exactly " at a very appropriate moment, but not otherwise regaining speech. No postmortem examination was made.

The cases related, so far as they bear on the question, are entirely corroborative of the view which assigns a close functional relation with articulate speech to that part of the upper edge of the fissure of Sylvius which forms the posterior end of the third frontal convolution of the left hemisphere. If this were the object of the paper I could give many similar cases, while $I$ have not met a single example of an opposite kind. The question being one of primary interest in cerebral physiology, I have examined all the apparently exceptional cases of which $I$ have been able to find the published record; and it is remarkable how large a proportion of them break down under careful scrutiny. Setting aside the distinction between the conditions to which the terms amnesia and aphasia have been applied, I have found, described under the head of aphasia, cases of labioglossc-laryngeal paralysis on the one hand and of dementia on the other, and again the speechlessness or indistinct articulation of patients who have never fully recovered from the shock of an apoplectic or convulsive attack, or of embolism of a large cerebral artery. Cases are quoted as examples of 
aphasia without disease of the left third frontal convolution in which the left middle cerebral artery, the nutrient vessel of the part, was blocked up; in which, therefore, the persistence of speech would have constituted a graver objection to the views in question, than its loss ; or in which, without apparent disease of the surface gray matter, the convolution was cut off from the central ganglia and the rest of the cerebrum by lesion of its white fibres; in some instances again the aphasia has been fugitive, and therefore dependent on some temporary condition, and yet the cases have been considered exceptional because no permanent lesion has been found after death. On the other hand, cases have been de. scribed as examples of disease of the left third frontal gyrus without affection of speech in which the description of the lesion clearly shows that the observer has taken some other convolution for the one named.

One or two examples only of coincidence of loss of speech with lesion of a given part of the cerebral hemisphere, unless their significance were entirely destroyed by the association of similar functional loss with lesions in other regions would suggest that the part in question was in some way concerned in the function of speech. In the case of that part of the upper edge of the fissure of Sylvius of the left hemisphere, which forms the posterior extremity of the inferior frontal convolution, the examples of coincidence are so numerous and the exceptions so few (some of these exceptions, too, occurring in left-handed subjects, when taken in connection with the hypothesis which makes the use of the left hemisphere in speech a concomitant of dextral pre-eminence, becoming strikingly corroborative), that it appears to me as reasonable to deny that the valves of the heart direct the course of the blood because we sometimes meet with cases in which the circulation has been carried on, notwithstanding changes in the valves which seem to have rendered it mechanically impossible, as to deny in the face of existing evidence that the convolution in question is in some way concerned in speech.

So much, then, will be taken for granted in the course of this communication, but it is not therefore to be supposed 
that lesion of this part of the hemisphere will be found in every kind of loss or derangement of language. It is not the seat of a "faculty of language," but simply a part of the nervous or cell and fibre mechanism, by means of which speech is accomplished, which mechanism may be damaged elsewhere above or below this particular node.

Previous writers (Bastian, Hughlings Jackson, W. Ogle, Sanders, and others) have pointed out that there are at least two distinct classes of cases in which speech is deranged or lost. 1. The amnesic or amnemonic, in which the patient has forgotten words; the idea no longer evokes the symbol, even in thought; the mental rehearsal of phrases is imperfect. 2. The ataxic or aphasic, in which the patient apparently remembers words, and rehearses sentences in his mind, but has lost the power of utterance; he has forgotten how to say words." Obviously, in these two classes of cases, the breach in the apparatus has occurred at quite different points. In amnesia the expression of an idea is interfered with at an earlier part of the "way out" than in aphasia, the defect is more strictly mental. To look for lesion in precisely the same part of the hemisphere in both cases can only lead to confusion, and confusion has thus arisen. Again, in each class the functional derangement may be (1) paralytic or (2) incoördinate. In paralytic amnesia the subject will have forgotten words, but will say them when they are suggested to him. In incoördinate amnesia he will have plenty of words, but will use wrong words, having probably little relation in either sound or sense to the words required, and he will be unconscious of the mistakes. In paralytic aphasia the patient will have lost the power of utterance, more or less completely, and will be unable to repeat words spoken in his hearing; in incoördinate aphasia he will use wrong words having some traceable relation to the word required, and he will be conscious of his mistake and try to correct it. Commonly two or more of these conditions are combined in various degree, and sometimes, in the course of a case, there is an apparent transition from one form to the other; for example, atactic aphasia may be recovered from, revealing 
amnesia, as in Case 2 in the paper. Dr. Hughling Jackson, who has insisted on the distinction between atactic and incoördinate affections of speech, has also pointed out that the one will probably depend on destruction of gray substance or white fibres; the other on instability of cells in cortical gray matter.

There is room, however, for further analysis of the conditions included under the term amnesia, which will be the more easily followed by reference to Case 8, that of Dunford. Here the mental powers were comparatively little impaired; the patient retained his shrewdness and humour; he conversed extremely well and wrote well; the faculty of intellectual expression was almost intact; but he was quite unable to read or even to name a single letter : and while the names of things came readily into his mind in the course of conversation, when he was asked the name of an object presented to his sight he could not recall it. Thus, while an object seen no longer evoked the appropriate name, the name and the object being presented simultaneously, were recognised as pertaining the one to the other, and the name recalled to mind the object. The visual image existed in the mind, the name existed in the mind, but the channel through which the former called up the latter was interrupted; on the other hand the channel by which the name recalled the image remained open. Naturally the defect was most conspicuous in the case of printed or written characters, as they are seen and remembered only in relation with intellectual symbols or words, and as visual objects are entirely subordinate. In other words involving more of theory, the supreme centres and the outward path from them to the proper motor centres were unaffected, but the upward track from the visual perceptive centre was cut across

Let us suppose an analogous condition with respect to articulate sounds-a severance of the auditory perceptive centre from the supreme or intellectual centre-so that spoken words no longer recall the mental conception with which they were previously associated. Words will now have lost their meaning, and it is conceivable 
that a patient may be capable of reasoning correctly ; but as the language of others will have no meaning for him, and as he has no check whatever upon his own words by the sense of hearing, and will thus have no idea whether he is saying what he wishes or not, he will be completely cut off from his fellow men unless, which is not likely, he can still read and write. It seems to me probable that cases of this kind occur, and that Cases 9 and 10 may be examples, as also the remarkable case quoted by Dr. Bastian from Dr. Banks.

Both as to mental condition and seat of lesion these cases would be different from amnesic and aphasic cases, the lesion occurring in one class in a part of the afferent nervous apparatus between the senses and the intellectual centres; in another in the intellectual centres themselves; in the third in the first part of the efferent nervous apparatus between the supreme centres and the motor ganglia.

Before I attempt to explain the hypothesis I have to advance as to the mechanism of thought and speech $I$ must give a brief outline of what I consider I have made out respecting the arrangement and distribution of the fibres of the cerebral hemispheres which form a part of that mechanism. My own researches have been mainly concerned with the fibres after they issue from the great eentral ganglia, the thalamus and corpus striatum, but the relations of the crura cerebri with these ganglia cannot be entirely left out of the consideration. It may be taken as established, more especially after the recent investigations of Meynert, that a large portion of the fibres of the crusta end in the cells of the corpus striatum and of the fibres of the tegmentum in the cells of the thalamus, while new fibres start in these ganglia and pass to the convolutions of the hemispheres. I do not accept the statement that all the fibres of the crus thus terminate, as I have repeatedly demonstrated the fact that many fibres, both of crusta and tegmentum, proceed to the convolutions without ever coming into relation with the gray matter of either of the central ganglia. I should add that from their position in the crus these fibres probably come from the cerebellum or from the gray matter of the pons. At their exit from the 
outer side of the corpus striatum and thalamus as the corona radiata the fibres from these two ganglia (and from the crus) become mixed up together so as to be indistinguishable, and no separate distribution can be traced except in a few situations, and they seem in fact to be distributed together to the same convolutions, though in different proportions. That such is the case is rendered more probable from the fact that certain convolutions, as for example, at the apex and outer edge of the temporo-sphenoidal lobe are reached by fibres from both corpus striatum and thalamus by totally different routes.

A further difficulty in the individualisation of distinct tracts of fibres arises from the interlacement of a part of the fibres of the corpus callosum with the radiating fibres emerging from the central ganglia, immediately on their exit. The fibres of the corpus callosum apparently connect symmetrically corresponding convolutions of the two hemispheres. At the outer edge of the lateral ventricles they meet the radiating central fibres, and the two sets of fibres are henceforth undistinguishable being apparently distributed to the same portions of the surface gray matter, this conclusion being corroborated by a consideration similar to that just mentioned with respect to the thalamus and corpus striatum, namely, that at certain parts, fibres radiating from the ganglia and fibres crossing transversely from one hemisphere to the other in the great commissure, reach the same point by different routes. Taking, then, central and callosal fibres together, without attempting to distinguish between them for the moment, it may be stated with confidence that they are not distributed uniformly to the convolutions, but that, on the contrary, there are extensive tracts of convolutions which receive no central or callosal fibres whatever. The convolutions to which these fibres pass are those forming the inner and outer margins of the hemisphere ${ }^{1}$ - the margin of the great longitudinal fissure on the one hand, and on the other, the margin formed successively

1 It may be here remarked that the modern current topographical classification of the convolutions is condemned by the disposition of the fibres, as it is also by inconsistency with the order of development.

voL. LV. 
by the third frontal, the upper edge of the fissure of Sylvius and the gyri along the same line to the occipital extremity of the hemisphere. The apex and the two margins of the temporo-sphenoidal lobe are reached by central and callosal fibres fewer in number and totally different in their course and mode of distribution. With the exception of the tip of the occipital lobe the proportion of central and callosal fibres increases from behind forward. I have already stated that these radiating and commissural fibres are so interwoven together as not to be followed separately, and they pass to the same parts of the surface of the hemisphere, but, while this appears to be the case, the fibres of the corpus callosum are distributed chiefly to the margin of the great longitudinal fissure, the fibres from the crus and central ganglia to the outer or Sylvian margin. ${ }^{1}$ The convolutions which are not in immediate relation with crus, central ganglia or corpus callosum by means of fibres are those of the Island of Reil, those on the under surface of the temporo-sphenoidal lobe, and of the orbital lobule, those on the flat inner aspect of the hemisphere, and those along the middle of the convex surface of the hemisphere from the occipital extremity as far forwards as the first ascending parietal gyrus (the second frontal appears to have central connections although in a less degree than the first and third). These tracts of the hemispherical gray matter are only indirectly connected with the ganglia and great commissure by means of fibres passing to the convolutions in direct communication with them. A large proportion of the white substance of the hemisphere consists of commissural fibres which associate together different parts of the surface gray matter, the superficial strands connecting neighbouring convolutions, the deeper layers uniting more distant points. Their general

1 When the corpus callosum is first formed it is continuous only with the flat inner surface of the hemisphere, which at this period is a hollow sac, while the continuity between the hemisphere and the central parts exists only in the outer wall around the fissure of Sylvius; and, although at a later stage of development, fibres are formed between the corpus callosum and the outer margin, and vice versá, the predominant distribution of central and callosal fibres is tc the parts with which they were originally connected. 
direction is longitudinal and neglecting details they fall into three great longitudinal systems-(1) that of the fasciculus uncinatus by which the convolutions below the level of the fissure of Sylvius are associated from the occipital to the frontal extremity of the hemisphere; (2) that of the gyrus fornicatus described by the late Mr. Solly, and called by him the superior longitudinal commissure ; and (3) the great axial longitudinal system of the hemisphere lying in the angle formed by the radiating and callosal fibres as they diverge to reach the upper and outer margins of the hemisphere respectively. In the system of the gyrus fornicatus are fibres which turn upwards round the splenium coporis callosi from the inner margin of the temporo-sphenoidal lobe, and a corresponding but more important mass of fibres bends inwards and upwards from the external convolutions of this lobe to turn forward in the very axis of the parieto-frontal part of the hemisphere, and distribute itself to the convolutions on the convex surface.

Now the convolutions which I have enumerated as having no direct communication with the crus, central ganglia or corpus callosum are, in the first place, those which are latest in order of development, and on this ground alone might be supposed to be concerned in the more strictly mental faculties which are latest in their manifestation; they are again those which constitute the difference between the human cerebrum and the cerebrum of the quadrumana; and it would, moreover, seem to accord with the general plan of construction of the nervous system and with what we know of the mental operations, that these convolutions which are withdrawn, so to speak, from direct relation with the outer world should be the seat of the more purely intellectual operations, receiving the raw material of thought from the convolutions on which sensory impressions impinge, and employing for the transmission outwards of the volitional product those convolutions which are in communication with the motor ganglia and tract.

The hypothesis I advance as to the mechanism of thought is essentially that of Dr. Bastian, which in effect $I$ 
adopt, giving to it, however, an important extension, and applying it also to the facts of cerebral structure. The essential points in Dr. Bastian's hypothesis I condense from his paper "On the Muscular Sense and on the Physiology of Thinking"' in the 'British Medical Journal' for May, 1869, employing as far as possible his own words :

1. It is presumed that in the higher phenomena of mind, which are dependent upon the cerebral hemispheres, certain definite parts of these are always called into activity whenever similar mental operations are repeated.

2. That when past impressions are revived as ideas or recollections, precisely the same parts of the hemispheres, the same nerve-fibres, and the same nerve-cells, must be called into activity, as were previously concerned in the perception of the original impression.

Here I shall have to introduce a qualification or add an explanation later.

3. That the several sense-centres at the base of the brain and in the medulla are connected in a perfectly definite way each with its own set of cells in the cortical substance of the hemispheres; these cells, in connection with the several sense centres constituting their respective "perceptive centres."

"In the perceptive centres the primary impressions made upon the organs of sense are converted into 'perceptions proper;' that is to say, they receive their intellectual elaboration, and this elaboration implies an intimate cell and fibre communication between each perceptive centre, and every other perceptive centre, since one of the principal features of a perceptive act is, that it tends to associate, as it were, into one state of consciousness much of the knowledge which has been derived at different times and in different ways concerning any particular object of perception. An impression of an object, therefore, made on any single sense centre on reaching the cerebral hemispheres, though it strikes first upon the perceptive centre corresponding, immediately radiates to other perceptive centres there to strike upon functionally related cells ; all this taking place with such rapidity that the several excitations are prac- 
tically simultaneous so that the combined effects are fused into one single perceptive act."

The full exposition of my hypothesis will occupy the remainder of the paper, but it will conduce to clearness to give here the modifications I make in the hypothesis of Dr. Bastian. It appears to me that the intellectual elaboration of impressions is divisible into two stages. There is a primary or rudimentary perceptive act in which the external cause of a given set of sensations is recognised as such, and in which the simple attributes, as of form, colour, hardness, \&c., are perceived. And there is a higher degree of elaboration in which, by the combination or fusion of perceptions derived from the various organs of sense, a conception or idea of an object as a whole is obtained. This is a new and distinct process, and is usually accompanied by the affixing of a name to the object. To the "perceptive centres" I relegate simply the translation of sensations into rudimentary or primary perceptions, and these centres must lie somewhere in the marginal convolutions, which receive radiating fibres from the crus and central ganglia; upon which, therefore, impressions will first impinge, and which are symmetrically combined by the fibres of the corpus callosum. The higher elaboration, the fusion of various perceptions together, and the evolution of an idea out of them, will be accomplished not by radiation of an impression from one perceptive centre to all the others, but by convergence of impressions from the various perceptive centres upon a common intermediate cell-area in which a process analogous to the translation of an impression into a sensation and of a sensation into a primary perception will take place. This intermediate cell. area will form a part of the supreme centre, and will be situate in the superadded convolutions which receive no radiating fibres.

A theory of the mechanism of thought should include an hypothesis as to the nervous change or nervous condition which is the concomitant of consciousness. The hypothesis I have formed is that in the nerve-cells, which are the seat of the particular state of consciousness, there is absorption of 
energy and integration of matter instead of the usual liberation of energy and disintegration of matter. Mr. Herbert Spencer has aptly compared the transmission of an impression along a nerve-fibre and the evolution of energy in a nerve-cell when reached by an impression to the firing of a train and explosion of a mine, and the comparison is true so long as the result is reflex action or retransmission onwards or upwards of an intensified nerve-motion. But when the impression reaching the terminal cells of the nervous system does not immediately result in movements, and is not transmitted farther, when, in fact, it gives rise to a sensation "vivid" or "faint," what becomes of the energy which constitutes the impinging impression, more especially, if in the nerve-cells here as elsewhere it determines an explosion? It appears to me clear that the energy of an impression communicated to cells which are the seats of sensation is expended in the production of some constructive change in the cell in the same way as luminous vibrations are fixed by constructive chemical changes in vegetables, and that the permanence of this change constitutes "memory." The seat of conscious sensibility will thus vary. It will be different, or at any rate the seat of the more frequently recurring and more important sensations will be different in different classes of animals. If the upper terminal segment of the nervous system be represented wholly or chiefly by the homologues of the central ganglia, the thalami or receptive ganglia will be the seat of sensations. As the hemispheres acquire relative importance the sensations or impressions will be radiated to their gray matter, and there undergo the primary intellectual elaboration which constitutes the simple perceptive act, or the higher elaboration which constitutes intelligence. Again, in the successive phases of development of the intellectual faculties in the human being there will be a gradual shifting upwards of the seat of the predominant states of consciousness -from the thalami, the seat of the simple rudimentary and general sensations of the infant, to the marginal convolutions of the hemispheres in immediate fibrous continuity with these ganglia as the fibres become differentiated and 
the paths constituted by them are opened by use in the child, and the general sensations of the infant are gradually specialised and defined into the perceptions of external nature as the cause of sensations;-finally, from the primary marginal convolutions to the superadded convolutions in which impressions relieve their full intellectual elaboration and highest degree of specialisation as childhood is left behind.

While, however, there is this upward shifting of the seat of the predominant states of consciousness, each of these original seats of sensation retains its elementary property, and many of our states of consciousness are compounded of sensations experienced simultaneously (as I think) or in rapid sequence (as most psychologists would say) in more than one ; and in certain circumstances an intense primary sensation as of acute pain dominates the secondary sensations radiating from its seat, (hypothetically) the thalamus, and takes entire possession of the consciousness, the excess of force, moreover, escaping outwards along motor tracts and giving rise to cries and muscular contortions.

The act of "thinking," or of cerebration as it has been called, will consist in the rapid transmission of fully elaborated impressions (here ideas, the product of secondary convolutions) from one cell-area to another in the same or in the opposite hemisphere along the complicated set of commissural fibres ascertained to exist, and this act will become automatic or fall into grooves by repetition and cease to be attended with conscious effort, just as in the case of the simple impressions concerned in learning to walk in another part of the nervous system.

It will be convenient to take first the mechanism of speech.

There are two distinct aspects in which words may be considered; 1, as motor processes; 2 , as intellectual symbols. A theory or hypothesis of language must trace their origin or mode of production from both points of view, and show their meeting point.

In the utterance of a word or series of words we have the co-operation of the thoracico-abdominal, laryngeal, guttural, lingual, and facial muscles. This implies the simultaneous 
and sequent excitation of numerous nerve-nuclei in the medulla and cord, and a most definite and exact co-ordination of the motor impulses issuing from them. Obviously the action of all these nuclei will be combined and directed by some higher centre.

Now, for movements of the face, tongue, and limbs, other than those of speech, the corpus striatum is known to be the centre immediately concerned. It stands between the hemisphere and the cord, and may be said to formulate into actions, the volitions transmitted downwards from the higher centres, i.e., it selects, so to speak, the particular motor nerve nuclei, which are appropriate for the desired movements, and calls them into action by impulses sent along the fibres passing from it to them. Putting this view into terms of cells and fibres a given movement will be represented by a particular grouping of cells in the corpus striatum, the descending processes of which are continued as fibres to particular nerve-nuclei. According to the character of the movements, general or special, will be the kind of cell-group in the corpus striatum, and the degree of co-ordinating action relegated to the cord; if the movements are general the corpus striatum cell-group will be small, simple, and capable of variation, the descending cell-processes and fibres few, while much will be left to the independent co-ordinating action of the cord ; when they are specialised the cell-groups in the corpus striatum will be large, complex, definite, little capable of variation, the descending processes will be numerous, the combined action of various nuclei in the cord and medulla will be effectuated by their means, and little will be left to the co-ordinating action of the cord. ${ }^{1}$ Either then the corpus striatum and its cells have the same function in speech as in the other modes of voluntary motion, in which case a word, or more strictly, an articulate sound, would be represented by a particular grouping of cells in this

' It is scarcely necessary to point out how this accords with the phenomena of common hemiplegia, the slighter paralysis and speedier recovery in the leg, in which movements are general, as compared with the arm, in which they are more special. 
ganglion, the descending processes of which pass to the cells of the nerve-nuclei concerned in its articulation, or there must be two distinct tracts of fibres from the higher centres to these nerve-nuclei, one from the corpus striatum for voluntary movements of the lips and tongue other than those of speech, and another from the frontal convolutions of the hemispheres for articulation. Now words, apart from their use as symbols, differ from other movements of the same parts only in their greater degree of specialisation, and we should not à priori expect a totally distinct apparatus to be employed in their production; again, the selection of a word as the proper vehicle of an idea, and the production of the articulate sound by setting in action the requisite movements are two distinct operations, and it is not likely that any part of the hemispherical cortex which we know to be mainly occupied in the various intellectual processes will be concerned in a mere matter of motor mechanism. At first sight, however, the second of these alternatives seems to be most consistent with the facts. We never have permanent loss of speech when the lesion is confined to the corpus striatum of the left side when our hypothetical word-groups therein contained will be destroyed. We frequently have loss of speech when the third left frontal convolution or the tract of fibres between it and the corpus striatum is damaged, this ganglion remaining uninjured. The conclusion seems unavoidable that the word-groups must be somewhere higher than the corpus striatum. A moment's reflection, however, will show that, supposing the third left frontal gyrus to be the seat of word-groups, or to be at least an important station on the "way out" for words, the further downward course of this road lies through the corpus striatum even if the cells of this body form no part of the mechanism, and in extensive lesions of the central ganglia this track for words could not fail to be interrupted, and thus, unless a way round from the left inferior frontal gyrus by the right corpus striatum exist, loss of speech should follow injury to the left corpus striatum. In other terms, if the downward course of words is repre. sented by a continuous tract of fibres from the third left 
frontal gyrus through the corpus striatum to the different nerve-nuclei there is no reason why, when this tract is cut across within the corpus striatum, the effects should differ from those of interruption of its continuity above the ganglion. Accordingly, the fact that damage limited to the left corpus striatum does not give rise to permanent loss of speech is equally a difficulty whether we suppose this ganglion to be the seat of the cell-groups representing words or consider that it is merely traversed by fibres, which are the downward channels of words, it being postulated always that the third left frontal convolution is an important link in the outward transmission of language. If, then, as I shall endeavour to show, there are reasons for believing that the word-groups are formed in each corpus striatum, right as well as left, the way round from the left third frontal gyrus to the right motor tract will be equally available in the two hypotheses $I$ have been comparing.

Returning now to words, and considering them as motor processes, they must be detached altogether from their use as symbols and looked upon simply as articulate sounds. We see an example of words acquired as motor processes without reference to their uses as intellectual symbols in the speaking of parrots and other birds; we, again, see words surviving as mere motor processes when all use for them in the communication of ideas has been lost, as in the case related by Dr. Bateman of a woman who automatically repeated everything she heard; or in the case of the priest, quoted by the same author, who, while imbecile and incapable of intelligent conversation, could recite long fables previously learnt by heart. It is one thing for a child to learn to utter a word, it is quite another thing for it to use words to express a meaning however simple. The utterance of words then consists in the acquirement of certain complex movements by imitation. A given articulate sound is heard : in learning to say it the effort is directed to the production of a similar sound; after a certain number of trials the proper adjustment is found, and, in the course of time, by continual practice, the adjustment for the production of any 
given sound is reached at once. It is to be observed that the power of adjustment thus acquired is not for words as such but for articulate sounds. A child learning to talk does not say one word well, and another not at all, but pronounces all imperfectly according to the difficulty they present in articulation to the particular child. A new word compounded out of old sounds is uttered at once, the adjustment for entirely new sounds is acquired late in life with extreme difficulty, if at all; witness the unconquerable foreign accent carried into another language. Now the education for this production of articulate sounds is through the ear ; the association formed is between impressions on the auditory nerve and movements of the lips, tongue, \&c., by which they can be imitated; the grouping of cells, then, in the centre from which motor impulses descend to the nervenuclei will take place under the control of the cells in the primary auditory perceptive centre, just as in reflex action, the motor impulses issuing from the cells of the anterior nerve-root are regulated by impressions received by and transmitted from the cells of the posterior nerve-root. The auditory perceptive centre will not be itself the seat of the motor sound-groups since in the general construction of the nervous system the receptive and emissive functions are assigned to different sets of cells, distinguishable according to recent observers, not only by their situation and relation with afferent and efferent sets of fibres but by their form and general appearance. Moreover, movements acquired under the direction of a sense-centre or at most primary perceptive centre, and having in themselves no more intellectual quality than any other movements of the same parts, will be represented by cell-groups in the same ganglion; namely, the corpus striatum and not in the hemispheres. But there is a peculiarity in the nerve-nuclei or sense-centres of the special senses, they are bilaterally associated; this, at least, is especially the case with the two intellectual senses of sight and hearing, and offers an explanation of the absence of unilateral blindness or deafness in hemiplegia with marked loss of common sensation in the limbs and trunk. The fused 
nerve-nuclei will constitute a common sense-centre which will send up fibres to each half of the cerebrum, and thus impressions will travel equally to the two hemispheres, and secondary or acquired automatic movements, such as those which give rise to articulate sounds, learnt through these special senses will be bilateral, and especially since the muscles, which are the agents in the production of the movements, are also bilaterally associated; that is to say, in objective terms the cell-groups representing articulate sounds will be formed in each corpus striatum.

The articulatory movements having become by practice automatic, which corresponds structurally to the completed grouping of the nerve-cells, the cell-groups may be variously employed: 1st. In parrot-like repetition of words without reference to their meaning. 2nd. In the exhibition of states of feeling. 3rd. In intellectual expression. That is, some cr all of these cell-groups, hypothetically located in the corpora striatum, may be called into action by impressions reaching them from at least three other centres. 1. The auditory perceptive centres; 2nd, the emotional centres; 3rd, the intellectual centres. This will be better understood from a reference to a more simple example. The portio-dura of the 7 th nerve is the agent $(a)$ in reflex movements, as of the eye-lid; (b) in emotional movements, such as smiles, \&c.; (c) in ordinary voluntary movements of the face. Now we have not a distinct set of fibres in the nerve for each of these kinds of action with a different central distribution; all the fibres of the nerve arise in the cells of its nucleus, and these cells are connected by processes and fibres with, and are called into action by the nucleus of the trigiminus for reflex movements, by some centre which is the outward channel for emotional expression, and by the centre by which volitional impulses are transmitted downwards. The same cells and fibres of the nucleus and nerve may be and are employed in all these forms of movement but differently grouped.

The word or sound groups being formed in each corpus striatum, the groups of the left side will take the lead in speech in consequence of the specialisation of the left 
hemisphere for intellectual expression. But, although, according to my observation, there is a more marked and more durable temporary embarrassment of speech in damage of the left than of the right motor ganglion, it is never completely lost when the lesion is limited to the corpus striatum. A way round then must exist by which impulses from the third left frontal convolution may reach the cell-groups in the right corpus striatum. The corpora striata have no proper commissure, and it is doubtful whether fibres in the corpus callosum connect these two bodies as well as the hemispheres, but apparently an indirect route is available by the fibres of the corpus callosum from the left to the right third frontal gyrus and thence to the corresponding corpus striatum. It is probable, indeed, that the two corpora striata habitually act together in speech through this indirect link. A certain time, however, is required to bring the new route into use, which explains the temporary affection of speech when the left corpus striatum is injured. When the lesion extends outwards or upwards from the corpus striatum into the white substance of hemisphere so far as to involve the fibres of the corpus callosum which connect the two inferior frontal gyri, or when the fibres from the left third frontal to the corresponding corpus striatum and those between the two gyri by the corpus callosum are cut across by disease in the white substance of the hemisphere not reaching the corpus striatum, language will be entirely lost. So, again, in extensive lesion of both corpora striata or of the left corpus striatum and right third frontal convolution, or in a variety of hypothetical cases which might be stated. On the other hand, the emotional escape of words in aphasia from lesion of the left hemisphere is easily understood if word-groups exist in the right corpus striatum.

No attempt is made here to explain the almost exclusive employment of the left hemisphere in intellectual expression, but, accepting this as a fact, the highly complex, definite, and special character of the volitions to be expressed in movements will imply an abundant and definite connection 
by fibres of some part of the hemispherical cortex with the word-groups in the corpus striatum, on the same principle that the cell-groups in this ganglion communicating with nervenuclei in the medulla and cord will be large and definite, and send off many descending processes when the movements to be executed are special and complex; whereas, when the movements are simple and general the cell-groups will be small and variable, and the descending processes few, the co-ordination being relegated to the cord. The anatomical fitness of that part of the upper edge of the fissure of Sylvius which forms the posterior end of the third frontal gyrus for the exercise of an important function, such as that of acting as the outlet for language, consists in the facts that it is one of the marginal convolutions which receives radiating and callosal fibres, and by means of its radiating fibres is in communication with the notor ganglion (corpus striatum) and tract, and that it has the most abundant and complicated connections with other convolutions to be met with in the brain. It receives fibres from the convolutions of the Island of Reil, from the infra-marginal convolutions of the fissure of Sylvius, and from parts posterior to it in the supramarginal convolution, from the second frontal and first frontal gyri, and from the orbital lobule, also from the two great longitudinal commissural systems, the axial and fasciculus uncinatus, by which it will be brought into relation with the convolutions on the convexity of the hemisphere and on the under surface of the temporo-sphenoidal lobe.

We come now to the consideration of words as intellectual symbols. From this point of view they are, in accordance with Dr. Bastian's theory, remembered sounds, and are probably represented in the auditory perceptive centre by receptive or recipio-motor cell-groups. A degree of persistence, resulting from frequent repetition of the impression, is a condition both of the formation of motor cell-groups for utterance, as already mentioned, and of the use of remembered sounds as symbols. In the act of naming, which constitutes the earliest intellectual or symbolic use of words, as the conception or idea of external objects is gradually formed by 
fusion of the visual, tactual, and other impressions to which it gives rise, the idea of the object is associated with an auditory impression used to designate it, and by an intellectual operation this auditory impression or name is made to stand for the resultant of the impressions generally. As has been already said, this process will consist in the convergence of impressions from the various perceptive centres upon an intermediate cell-area in the superadded convolutions, where they are combined and elaborated into an idea of which the word is the symbol. This intellectual elaboration and the formation of the motor word or sound-group are two entirely different and independent processes-one is sensory education, the other motor education. A child knows the names of most of the familiar objects by which it is surrounded long before it attempts to talk, and there is no constant relation between the general intelligence of a child, as manifested by comprehension of what is said, and its ability to talk. The case of congenital aphasia given in this paper is a striking illustration of this fact. A word considered simply as an auditory impression, and as such produced by parrot-like imitation, and a word used as a name, that is, as the vehicle of an idea differ essentially; they will be revived in different parts of the hemispherical cortex, and an impulse for the utterance of the word will reach the corpus striatum by a different route in the two cases. The revival of the name in the higher centre may be effected by an impression arriving through the auditory perceptive centre, by the same means, in fact, by which it was originally implanted, or it may be revived through impressions, or ideas with which it has become almost indissolubly associated in the higher centre. I have up to the present been speaking of words employed as names, or of nouns substantive, which is the first use of words by the child in acquiring the faculty of language. Words other than names, such as adjectives, verbs, \&c., constituting the framework of a sentence or proposition, stand on a different footing; they are not associated with and tied down by visual, tactual, and other perceptions. Their use implies a previous knowledge of words 
as names, and marks a step beyond the act of naming (which is a part of what $I$ have called sensory education, in which the supreme centres receive and combine or associate impressions) in the direction of propositionising and intellectual expression in which the supreme centres play an active part, and begin to transmit impulses outwards. They are not substantive intellectual symbols, but intellectual agents, instruments and products of intellect in action, not presentations impressed upon it. It is with respect to this class of words that it may be strictly said that "we think in words," for we often think in revived visual impressions not reduced to words. The convolutions concerned in their employment will be such as are the seat of the intellectual operations, the superadded convolutions. Even as regards the auditory perceptive centre, by means of which the sound-groups in the corpus striatum representing them were formed, these words are not revived as objects of consciousness, but the soundgroups are used automatically. These considerations enable us approximately to understand how names may be forgotten while the framework of a sentence is readily uttered, and even a periphrasis invented for a required name.

Words, as intellectual symbols or agents, have now been followed to the supreme centres or superadded convolutions; as motor processes they have previously been followed to the third left frontal convolution, which is supposed to select the words for the expression of an idea, and play upon the preformed wordgroups in the corpora striata, as these ganglia in their turn select and play upon the nerve-nuclei and muscles for the production of movements. Where exactly the process of reasoning and propositionising or framing for expression the product of intellectual action takes place cannot be stated, probably the whole area of superadded convolutions of both hemispheres is engaged in it; nor is the route known by which propositions pass to the third left frontal gyrus for expression. Apparently the action of the hemispheres is bilateral as far as the formation of rudimentary perceptions, since the convolutions upon which sensory impressions brought by the radiating fibres impinge are connected together symmetrically by the corpus 
callosum. The unilateral employment of one hemisphere in intellectual expression revealed by pathology apparently becomes possible only in the superadded convolutions, which are not bilaterally associated, and the unilateral education by which M. Broca and Dr. Moxon explain the pre-eminence of the left hemisphere in intellectual expression is a motor or rather efferent education only.

Reading and writing have been kept out of sight for the sake of clearness. It will not be difficult to apply the same line of reasoning to this form of language with the modification required by the consideration that it is engrafted upon and acquired through spoken language, and not directly as is the latter.

Resuming briefly the points with regard to words which embody the theory here advanced of language as the instrument and vehicle of thought :

1. Words, as remembered sounds, will be represented by cell-groups at the summit of the receptive side of the nervous system, which, for reasons given, is supposed to be situated in the marginal convolutions of the hemisphere.

2. From these cell-groups, when definitely formed, impressions will be transmitted to a cell-area in the superadded convolutions, to which also impressions conveying to the mind the various properties of objects indicated by the words will be transmitted; all these impressions are associated, and the word is employed as the symbol for the resulting idea of the object.

3. Almost simultaneously motor cells in the corpus striatum are grouped for the production of articulate words under the guidance of the remembered sound in response to efforts at imitation, which are at first more or less parrot-like. The cell-groups for spoken words once formed are, however, employed almost exclusively in intellectual expression. ${ }^{1}$

1 The child learns to walk and talk because it sees and hears other walk and talk. The man walks in order to go from place to place; he talks to convey ideas. In learning to walk the child gives attention to the act of walking, but the concatenation of cells and fibres by which walking becomes automatic is spinal, as is seen from locomotor ataxy. So in learning to talk, the formation

voL. $\mathbf{L V}$. 
4. The receptive cell-groups for remembered sounds will be found in the marginal convolutions of the two hemispheres which are symmetrically associated by the corpus callosum, and the cell-groups for spoken sounds will be found in the Two corporæ striatæ, but the absence of commissural connection between the superadded convolutions of the two hemispheres permits of the predominant, if not exclusive, education of the left hemisphere for the verbal expression of the product of intellectual action, as has been revealed by pathology. This is an efferent process, and does not imply the exclusive use of the hemisphere in thought.

5. The outlet for intellectual expression in spoken words, which are motor acts, is necessarily in some part of the marginal convolutions in relation by fibres with the corpus striatum, and pathology has shown this point to be the left third frontal gyrus.

6. The left third frontal gyrus being the outlet for expression, the left corpus striatum necessarily takes the lead in the production of spoken words, but a way round exists probably from the left to the right third frontal gyrus by the corpus callosum, and thence to the right corpus striatum. Thus speech, though temporarily embarrassed by damage to the left corpus striatum, is recovered; whereas, if the cortex of the left third frontal convolution is damaged, or its fibres, both to corpus striatum and corpus callosum, cut through, speech, having no other outlet, is lost.

The mechanism of thought has been so far explained in the consideration of the mechanism of speech that it need not be followed in detail.

of automatic word-groups, though prompted by the growing intelligence, is effected by means of the auditory sense or perception centre. 